\title{
24-Hour Proteinuria Weakly Correlated with Estimated Glomerular Filtration Rate in Lupus Nephritis Patients
}

\author{
Suhendra Praptama' ${ }^{1}$ Yulia Hayatul Aini², Mohammad Ghozali ${ }^{3}$, Laniyati Hamijoyo ${ }^{4}$
}

${ }^{1}$ Faculty of Medicine,

${ }^{2}$ Department of Clinical Pathology, ${ }^{3}$ Department of Biochemistry and Molecular Biology, ${ }^{4}$ Department of Internal Medicine, UniversitasPadjadjaran / Dr. Hasan Sadikin General Hospital, Bandung, Indonesia

\begin{abstract}
Background: Lupus Nephritis (LN) is still the most frequent complication in Systemic Lupus Erythematous (SLE) patients which causing the major and significance morbidity and mortality. Proteinuria and Glomerular Filtration Rate (GFR) serves as objective and routine examinations to assessrenal function. 24-hour proteinuria still regarded as gold standard to quantify amount protein in urine. Estimated GFR (eGFR) is preferably used due its convenient. On the hand, estimated GFR (eGFR) is preferably used due its convenient. However, both of them should be measured in order to determine renal progression and prognosis. Only few studies have been conducted to find out the correlation between 24-hour proteinuria and eGFR in lupus nephritis patients as both of them serve as potential marker in progression of renal involvement. This study addressed to find out correlation between 24-hour proteinuria and eGFR in lupus nephritis patients.
\end{abstract}

Method: Analytic-correlation study with cross-sectional approach at Dr. Hasan Sadikin Hospital, Bandung was done. Secondary data was used and paralleled with previous study entitled "Correlation of Random Urine Protein Creatinine (P-C) Ratio with 24-Hour Protein Urine in Lupus Nephritis Patients" carried out from October to December 2014.Correlation coefficient was analyzed by Spearmans' correlation test.

Results: Forty five samples were obtained based on inclusion criteria. Spearmans' correlation test revealed non significant and very weak correlation between 24hour proteinuria and eGFR ( $r=-0.095)$ with $p>0.05$.

Conclusion: The 24-hour proteinuria and eGFR are weakly correlated. Despite the weak correlation, these examinationsshould be considered as important markers to monitor prognosis of renal involvement in lupus nephritis patients

Keywords: Estimated glomerular filtration rate (eGFR), Lupus Nephritis (LN), Proteinuria, Systemic Lupus Erythematosus (SLE).

\section{Background}

Systemic Lupus Erythematosus (SLE) is a chronic autoimmune disease with multisystem clinical manifestations and complications ranged from decreasing quality of life until death. ${ }^{(1,2)}$ Around $60 \%$ of SLE patients' will suffer of renal involvement, lupus nephritis (LN), which significantly increase their morbidity and mortality. ${ }^{(3,4)}$ Mortality rate in SLE patient with LN is8-fold higher than SLE patients without renal involvement. ${ }^{(5)}$ Around $17 \%$ LN patients will develop chronic kidney disease (CKD) or terminal stage of renal failure. This condition caused the requirement of a lifetime hemodialysis or expensive renal transplantation..$^{(6,7)}$

Most of LN are clinically asymptomatic due to slow declining progression ofrenal function. (8) Both of Glomerular Filtration Rate (GFR) and proteinuria are currently used to assess kidney function. ${ }^{(9)}$ Estimated GFR (eGFR) is preferably used instead of inulin clearance due its convenient and strong correlation with GFR..$^{(9,10)}$ On the other hand, proteinuria is also a strong independent predictor of the declining GFR and serves as prognostic factor in chronic kidney disease. ${ }^{(3,11)}$ The 24-hour urine collection is still regarded as gold standard of proteinuria measurement although alternative methods are already proposed. ${ }^{(11)}$ Several studies revealed proteinuria associates with the fasten progression of renal function declining and serves as an important marker in the etiology of lowered eGFR. ${ }^{(12)}$ In addition, patients with heavy proteinuria and normal eGFR have higher mortality rate compared to those with low or no proteinuria and low eGFR. ${ }^{(13)}$ Hence, it is important to assess both proteinuria and eGFR in patients with renal dysfunction, especially in lupus nephritis where renal flare might be occured anytime. ${ }^{(4)}$ Only few studies have already carried out to discover the correlation of $24-\mathrm{H}$ proteinuria and eGFR in $\mathrm{LN}$ patients. ${ }^{(14)}$ This study was addressed to find out the correlation between 24-hour proteinuria and eGFR in lupus nephritis patients.

\section{Method}

We conducted an analytic-correlative study with cross-sectional approach at Dr. Hasan Sadikin Hospital, Bandung. This study used secondary data and paralleled with previous study entitled "Correlation of Random Urine Protein Creatinine (P-C) Ratio with 24-Hour Protein Urine in Lupus Nephritis Patients"(15) carried out from October to December 2014. This study has alreadyapproved by Health Research Ethics Committee in Hasan Sadikin General Hospital.

The subjects of this study were patients who had been diagnosed as lupus nephritis based on American College of Rheumatology, came to 
Rheumatology Wards in Hasan Sadikin General Hospitalon October to December 2014 have regular control. Minimum sample required in this study is 141 . However, total sampling method used because only 45 data were available. Eligible sample selected based on inclusion criteria: available data of complete laboratory test of 24-hour proteinuria and eGFR; and exclusion criteria: patients who were having menstruation, and suffered from other glomerulopathies, urinary tract infection, and inadequate 24-hour urine. ${ }^{(15)}$

Data analysis includes: sample demographic charactertics, such as age, gender, and duration of having SLE; proteinuria measured by 24-hour urine collection method; and eGFR calculated by Cockcroft-Gault ${ }^{(4)}$. Proteinuria was classified based on protein urine excretion level into 3 groups (minimal, moderate or non nephrotic, heavy or nephrotic). eGFR was classified based on "CKD prognosis on Kidney Disease: Improving Global Outcomes (KDIGO)" into 6 groups (Grade $1,2,3 \mathrm{a}, 3 \mathrm{~b}, 4,5)$.

Distribution of the data was analyzed by Shappiro-Wilk test. Furthermore, 24-hour proteinuria and eGFR analyzed by Spearmans correlation test and $\mathrm{p}<0.05$ considered statistically significance. ${ }^{(16)}$ Statistical analysis was performed using statistical analysis software.

\section{Result}

This study involved 45 persons. The subjects' characteristics are presented in Table 1.

Table 1 Characteristic of the samples

\begin{tabular}{ll}
\hline \multicolumn{1}{c}{ Variable } & \multicolumn{1}{c}{ Result (45 subjects) } \\
\hline Age (years, Mean \pm SD) & $32,23 \pm 10,95$ \\
Gender,n(\%) & \\
- Female & $44(97.8)$ \\
- Male & $1(2.2)$ \\
Duration SLE, $n(\%)$ & \\
- $<1$ year & $10(22.2)$ \\
- $\geq 1$ year & $35(77.78)$ \\
\hline
\end{tabular}

The 24-hour proteinuria was classified based on amount of protein urine excretion each into different groups as shown in Table 2.

Table 2 Characteristic of 24-hour Proteinuria

\begin{tabular}{lcc}
\hline \multicolumn{1}{c}{ Variable } & Median & Range \\
\hline 24-hour proteinuria (mg/24 hours) & 387,5 & $52,90-5800$ \\
Classification based on protein urine & N (\%) & \\
excretion & & \\
- Minimal & $31(68.9)$ & \\
- moderate & $12(26.7)$ \\
- Nephrotic or heavy & $2(4.4)$ \\
\hline
\end{tabular}

Minimal $=$ proteinuria $<1000 \mathrm{mg} / 24$ hours; moderate $=$ non nephrotic, proteinuria $1000-3500 \mathrm{mg} / 24$ hours; heavy $=$ nephrotic, proteinuria $>3500 \mathrm{mg} / 24$ hours
The eGFR was classified based on grading of CKD in KDIGO guideline each into different groups as shown in Table 3.

Table 3 Characteristic of Estimated Glomerular Filtration Rate (eGFR)

\begin{tabular}{lll}
\hline \multicolumn{1}{c}{ Variable } & \multicolumn{1}{c}{ Median } & \multicolumn{1}{c}{ Range } \\
\hline Estimated Glomerular Filtration Rate $(\mathrm{ml} / \mathrm{min})$ & 89,360 & $11,66-268,68$ \\
KDIGOs' classification of CKD & $\mathbf{N}(\%)$ & \\
- Grade 1 & $22(48,9)$ \\
- Grade 2 & $16(35,5)$ \\
- Grade 3a & $2(4,4)$ \\
- Grade 3b & $4(8,9)$ \\
- Grade 4 & $0(0)$ \\
- Grade 5 & $1(2,2)$ \\
\hline
\end{tabular}

Grade $1=$ normal $/$ high, eGFR $\geq 90 \mathrm{ml} / \mathrm{min} ;$ Grade $2=$ Mildly decreased, eGFR $60-89 \mathrm{ml} / \mathrm{min}$; Grade $3 a=$ Mildly to moderately decreased, eGFR $45-59 \mathrm{ml} / \mathrm{min}$; Grade $3 \mathrm{~b}=$ Moderately to severely decreased, eGFR 30-44 ml/min; Grade $4=$ Severely decreased, eGFR $15-29 \mathrm{ml} / \mathrm{min}$; Grade $5=$ Kidney failure, eGFR $\leq 15 \mathrm{ml} / \mathrm{min}$.

The 24-hour proteinuria was classified based on protein urine excretion and cross tabulated with eGFR based on KDIGO classification were presented in Table 4:

Table 4 Cross tabulation frequency of 24-hour proteinuria and eGFR

\begin{tabular}{|c|c|c|c|c|c|c|}
\hline \multirow{2}{*}{$\begin{array}{c}\text { 24-hour } \\
\text { Proteinuria } \\
\text { (mg/24 hours) }\end{array}$} & \multicolumn{6}{|c|}{$\begin{array}{c}\text { eGFR ml/min }[n(\%)] \\
\text { KDIGO }\end{array}$} \\
\hline & G1 & G2 & G3a & G3b & G4 & G5 \\
\hline Mild & $16(35.8)$ & $12(26.8)$ & $1(2.2)$ & $2(4.4)$ & $0(0.0)$ & $0(0.0)$ \\
\hline Moderate & $4 \quad(8.8)$ & $4 \quad(8.8)$ & $1(2.2)$ & $2(4.4)$ & $0(0.0)$ & $1(2.2)$ \\
\hline Heavy & $2(4.4)$ & $0(0.0)$ & $0(0.0)$ & $0(0.0)$ & $0(0.0)$ & $0(0.0)$ \\
\hline Total & $22(49.0)$ & $16(35.6)$ & $2(4.4)$ & $4(8.8)$ & $0(0.0)$ & $1(2.2)$ \\
\hline
\end{tabular}

24H-Proteinuria: Minimal= proteinuria $<1000 \mathrm{mg} / 24$ hours; moderate $=$ non nephrotic, proteinuria $1000-3500 \mathrm{mg} / 24$ hours; heavy $=$ nephrotic, proteinuria $>3500 \mathrm{mg} / 24$ hours;

eGFR: Grade $1=$ normal/high, eGFR $\geq 90 \mathrm{ml} / \mathrm{min}$; Grade $2=$ Mildly decreased, eGFR $60-89 \mathrm{ml} / \mathrm{min}$; Grade $3 a=$ Mildly to moderately decreased, eGFR $45-59 \mathrm{ml} / \mathrm{min}$; Grade $3 \mathrm{~b}=$ Moderately to severely decreased, eGFR 30-44 ml/min; Grade $4=$ Severely decreased, eGFR $15-29 \mathrm{ml} / \mathrm{min}$; Grade $5=$ Kidney failure, eGFR $\leq 15 \mathrm{ml} / \mathrm{min}$.

Graph of analytical correlation test between 24-hour proteinuria and GFR used Spearmans' correlation test was shown in Figure 1. 
Figure 1 Correlation between 24-hour Proteinuria and eGFR

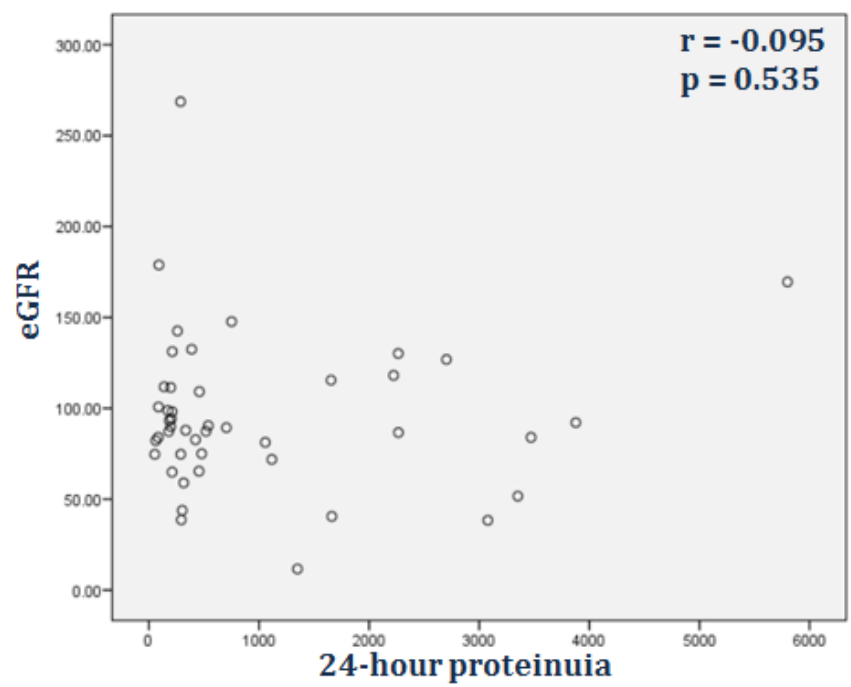

Discussion

Our study reveals female has higher prevalence $(97.8 \%$ of patients) than the male. Most of subjects (77.78\%) have been diagnosed as SLE for more than 1 year. Most of subjects have mild proteinuria following by higher eGFR. We found a very weak correlation between 24-hour proteinuria and eGFR.

Proteinuria serves as an important marker in diagnosing lupus nephritis, when renal biopsy can not be performed. (7,9) Most of the proteinuria was found with the range from moderate to heavy nephrotic level. ${ }^{(9,17)}$ So did in our study, which reveals $31.1 \%$ patients who had moderate to heavy proteinuria. This result was also in line with the previous study conducted by Sircar, et al., in which revealed $42 \%$ patients with nephrotic proteinuria. ${ }^{(14)}$

Glomerular Filtration Rate is a gold standard measurement of renal function, particularly to determine CKD grade and prognosis. ${ }^{(18,19)}$ However, our study used eGFR as an alternative method of GFR measurement, since it is more convinient and most data had not provided the GFR measurement. ${ }^{(10)}$ Our study revealed $84.4 \%$ of patients have low risk on CKD based on KDIGO classification G1 and G2. It reflected that most patients are well treated that resulted a significant renal improvement. Chronic kidney disease could not be diagnosed in this study, since the measurement of GFR was only taken once, whereas it requires, at least, 3 month to monitor eGFR progression to be termed as chronic kidney disease. Unfortunately, some of our subjects were also encountered declining of renal function even though receiving adequate therapy. It requires further analysis to determine any factors that affected to this result.

Both of proteinuria and eGFR are routinely measured to monitor renal function, specifically in patients with high proteinuria and low eGFR level. ${ }^{(13)}$ This study reveals that most of patients who has mild proteinuria level exhibited normal or higher eGFR, as previously mentioned. However, there were $4.4 \%$ of patients had heavy proteinuria encountered with normal or higher eGFR based on KDIGO. This condition is diagnosed as membranous lupus nephritis, by considering the proteinuria level rather than GFR. ${ }^{(9)}$ Study conducted in Eastern India revealed a significant and negative weak correlation between proteinuria and GFR. ${ }^{(14)}$ The negative correlation result between the variables reflected higher level of proteinuria may lowered eGFR, hence proteinuria becomes a potential marker to determine renal dysfunction. ${ }^{(3,13)}$ However, our study revealed no-significant and very weak correlation between 24-hour proteinuria and eGFR. We suggested that the no-significant and weak correlation results were impacted by the treatment gotten by each patients thus most of patients had already shown renal improvement. Furthermore, this result also implicated correlation between 24-hour proteinuria and eGFR is promising markers in order to assess kidney function as both of them serve as routine and objective examination in lupus nephritis patients. ${ }^{(3,9,11)}$

Several studies have already conducted to discover the correlation between proteinuria and GFR shown various result. ${ }^{(18-21)}$ They reported proteinuria plays a significant role in declining GFR, and both of them should be measured to assess renal function. ${ }^{(12,13,20)}$ Proteinuria can be markers for both glomerular dysfunction and renal disease progression. ${ }^{(21)}$ However, this study reveals very weak correlation between 24-hour proteinuria and eGFR in lupus nephritis. Most of patients have normal or higher eGFR and mild proteinuria even though diagnosed as lupus nephritis. This result most likely confounded by treatment undergone by the subjects, hence most of them show renal improvement based on proteinuria and eGFR level.

Limitations of this study are samples only taken in once and minimum samples are not fulfilled. Every patients involved in this study had already received therapy that becomes potential confounding in this study. So, we cannot provide baseline data of patients before undergoing therapy.

\section{Conclusion}

Based on this study, it is concluded there is a very weak correlation between 24-hour proteinuria and eGFR in lupus nephritis patients.Despite the weak correlation, these examinationsshould be considered as important markers to monitor prognosis of renal involvement in lupus nephritis patients. Further studies should be reattempted to evaluate these results by taking the sample periodically in order to monitor eGFR, considering its convenient and cost-effective method.

\section{References}

1. Afzal N, Shehzad F, Rasheed S. Systemic lupus erythematosus - an immunological disorder. Biomedica. 2014 Sept;30(3):1-9.

2. George Bertsias, Ricard Cervera DTB. Systemic Lupus Erythematosus: Pathogenesis and Clinical Features. In: Bijlsma JWJ, editor. EULAR Textbook on Rheumatic Diseases, $1^{\text {st }}$ edition. Zurich: BMJ; 2012: 476505.

3. Corapi KM, Dooley MA, Pendergraft WF. Comparison and evaluation of lupus nephritis response criteria in lupus activity indices and clinical trials. Arthritis Res Ther. 2015;17(1):110.

4. Saxena R, Mahajan T, Mohan C. Lupus nephritis: current update. Arthritis Res Ther. 2011;13(5):240. 
5. Rasić S, Srna A, Uncanin S, Dzemidzić J, Rebić D, Muslimović A, et al. Long-term outcome of patients with lupus nephritis: a single center experience. Bosn J Basic Med Sci. 2010;10 Suppl 1/Supplement 1):S63-67.

6. Eilertsen GØ. Clinical epidemiology of Systemic Lupus Erythematosus with emphasis on nephritis and autoantibody production [Internet]. University of Tromsø; 2011 Sept.

7. Kasjmir Y, Handono K, Wijaya LK, Hamijoyo L, Albar Z, Kalim H, et al. Indonesian Rheumatologist Association Recommendation of systemic lupus erythematosus: diagnosis and management. Jakarta: IRA; 2011:154

8. Kronbichler A, Mayer G. Renal involvement in autoimmune connective tissue diseases. BMC Med. BMC Medicine; 2013;11(1):95.

9. Hahn BH, McMahon M a., Wilkinson A, Wallace WD, Daikh DI, FitzGerald JD, et al. American College of Rheumatology guidelines for screening, treatment, and management of lupus nephritis. Arthritis Care Res (Hoboken). 2012;64(6):797-808.

10. Wong S-N, Chan WK-Y, Hui J, Chim S, Lee T-L, Lee K-P, et al. Membranous lupus nephritis in Chinese children--a case series and review of the literature. Pediatr Nephrol. 2009;24(10):1989-1996.

11. Naderi ASA, Reilly RF. Primary care approach to proteinuria. J Am Board Fam Med. 2008;21 (6):569-574.

12. Miyatake N, Shikata K, Makino H, Numata T. The relation between estimated glomerular filtration rate and proteinuria in Okayama Prefecture, Japan. Environ Health Prev Med. 2011;16:191-195.

13. Hemmelgarn BR. Relation Between Kidney Function, Proteinuria, and Adverse Outcomes. Jama. 2010;303(5):423.
14. Sircar D, Sircar G, Waikhom R, Raychowdhury A, Pandey R. Clinical features, epidemiology, and short - term outcomes of proliferative lupus nephritis in Eastern India. Indian J Nephrol. 2015;5-11.

15. Aini YH, Tjandrawati A, Suraya N, Hamijoyo L. Correlation between 24hour Proteinuria and Urine Protein Creatinine Ratio in Lupus Nephritis Patients. Indones J Rheumatol. 2014;8(1):24-29.

16. Hulley SB, Cummings SR, Browner WS, Grady DG, Newman TB, editor Designing Clinical Research, $4^{\text {th }}$ ed. Philadelphia: Lippincott Williams and Wilkins; 2007:351

17. Ezzra J, Zhao S, McPherson R. Urine and Other Body Fluids. In: Henry's, editor. Clinical Diagnosis and Management by Laboratory Methods. 21st ed. Philadelphia: Saunders Company; 2007:394-424.

18. Kapoor S, Rastogi K, Verma A, Kumar M, Saxena I. Assessment of Proteinuria by the Determination of Micro Total Protein and Estimated Glomerular Filtration Rate in Type 2 Diabetes Mellitus Patients. Intern J Sci Study. 2014;2(9):27-31.

19. Dall'era M, Wofsy D. Clinical Features of Systemic Lupus Erythematosus. In: Firestein GS, Kelley WN, editor. Kelley and Firestein's Textbook of Rheumatology, 9th ed. Philadelphia: Saunders Elsevier; 2013: 16801691.

20. Turin TC, James M, Ravani P, Tonelli M, Manns BJ, Quinn $R$, et al. Proteinuria and Rate of Change in Kidney Function in a Community-Based Population. 2013;1661-1667.

21. Lin GG, Scott JG. Outcome and Predictors of Kidney Disease Progression in Puerto Ricans with Systemic Lupus Erythematosus Initially Presenting with Mild Renal Involvement. J Clin Rheumatol. 2012;100(2):130-4. 